\title{
Incidence And Risk Factors Of Maternal And Fetal Outcomes Among Patients Of Placenta Previa With And Without Placenta Accreta
}

\author{
Samina Naseem Khattak, Umbreen Akram, Erum Pervaiz, Maria Anayat, Tahir Ahmad Munir, Naheed Akhter, \\ Athar Ahmad Jan \\ $-----------------------------------$
} ABSTRACT:

Objective: The aim of the study was to evaluate maternal and fetal outcomes among patients of placenta previa (PP) with and without placenta accreta (PA).

Methodology: All patients who underwent cesarean section for PP and PA were analyzed retrospectively at a tertiary care Combined Military Hospital Kharian, Pakistan, from February 2015 to March 2018. Maternal and neonatal data were obtained from medical records and the hospital database system.

Results: PA was found in 37 patients from 111 patients of PP and 74 were without PA with the rate of approximately 2/1000 and 4/1000 respectively were included in the study. The mean age was $31.16 \pm 2.65$ (range $22-37$ ) years, mean gravidity of $3.69 \pm 1.40$ (range 1 - 9), mean parity $2.57 \pm 1.01$ (range $1-5$ ), mean number of cesarean sections $2.10 \pm 0.66$, (range $1-3$ ) and a mean gestational age at the time of cesarean section was $35.65 \pm 2.46$ (range 28-41) weeks. The maternal risk factors revealed marked differences between placenta previa with accreta and without accrete. The mean intraoperative blood loss in PA was $3,000 \mathrm{ml}$, with a loss of $2,000 \mathrm{ml}$ occurring in $60 \%$, and $3,000 \mathrm{ml}$ in $21 \%$ of the PA cases. The mean pRBC transfusion was 4 units, while 17\% received 6 units. Fetal growth restriction was not seen. A total of 12 neonates were admitted in NICU, with 03 neonatal deaths. There was no maternal death. Neonates born to women with placenta accreta had significantly lower birth weight, Apgar scores at 1 min and 12\% required admission to NICU with 3 neonatal deaths.

Conclusion: The advanced maternal age, past cesarean or uterine surgery, high parity as well as multiple gravidity were the risk factors for adverse fetal and maternal outcomes.

Key Words: Placenta previa, Placenta accreta, maternal outcome, Neonatal outcome.

\section{INTRODUCTION:}

Hemorrhage and the hypertensive disorders are the primary cause of maternal morbidity and mortality in the developed and developing world. The placenta accreta and its related pathologies are the leading cause of maternal hemorrhage

Samina Naseem Khattak

I Assistant professor, Department of Gynecology and Obstetrics I Combined Military Hospital Kharian Pakistan

I Umbreen Akram

I Assistant professor, Department of Gynecology and Obstetrics I Combined Military Hospital Kharian Pakistan

| Erum Pervaiz

Assistant professor, Department of Gynecology and Obstetrics I Combined Military Hospital Gilgit Pakistan

Maria Anayat

Resident, Department of Gynecology and Obstetrics

I Combined Military Hospital Kharian Pakistan

I Tahir Ahmad Munir

I Professor, Department of Physiology,

Mohi-ud-din Islamic Medical College, Mirpur, Azad Kashmir. I

I Naheed Akhter

Assistant Professor, Department of Medicine,

Combined Military Hospital Institute of Medical Sciences,

I Bahawalpur.

Email: naheedimam@gmail.com

I Athar Ahmad Jan

Student 4th year MBBS,

I Changde Medical University China

Received: 31-07-2018

Accepted: 21-12-2018

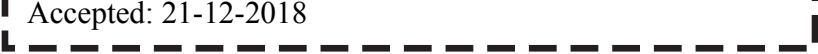

and cesarean hysterectomy ${ }^{1}$. The PA defined as the placenta being adherent to the uterine wall without easy separation; was confirmed by clinical assessment, gray scale ultrasound done, evidence of gross placental invasion at the time of surgery or by pathologist proving adherence of placental villi to the myometrium without intervening decidua basalis ${ }^{2}$.

Deficiency of decidua basalis at the endometrial scar is thought to be the cause of placenta accreta. The decidual or trophoblast induced vascular remodeling are such disturbed that the myometrium is invaded deeply by the trophoblast. These larger diameter vessels conduct a greater blood volume than the smaller diameter spiral arteries, resulting massive intrapartum hemorrhage associated with high maternal morbidity and mortality at time of placental removal ${ }^{2,3}$. The extreme variants of accreta include increta and percret. The risk factor for placenta accreta includes lower uterine segment implantation, damage or scarring due to dilatation and curettage (D\&C) and myomectomy ${ }^{4,5}$.

The placenta accreta has increased the rate of cesarean section by 10 folds since $1950 \mathrm{~s},{ }^{6}$ the current rates range from $1 / 533$ to $1 / 7000$ live births in developed countries resulting a mortality rate of approximately $7 \%{ }^{1}$ however, other reasons to increase in cesarean delivery include assisted reproductive technology and older maternal age ${ }^{6}$. Ultrasound findings suggestive of placenta accreta include, loss of normal hypoechoic retroplacental zone, retroplacental myometrial thickness of $<1 \mathrm{~mm}$, "swiss cheese" appearance, numerous coherent vessels and blood vessels or placental 
tissue bridging uterine-placental margin, myometrial-bladder interface, or crossing the uterine serosa ${ }^{7,8}$.

Multidisciplinary team planning is required for mode of delivery as the uterine surgery may compromise future fertility, or radiological interventions to reduce maternal and neonatal morbidity ${ }^{9}$. The aim of the study was to evaluate maternal and fetal outcomes among patients of placenta previa (PP) with and without placenta accreta (PA).

\section{METHODOLOGY:}

This study was carried out in CMH Kharian Pakistan after taking approval from the ethical committee of the hospital. The hospital records from February 2015 to March 2018 were assessed and all patients who underwent caesarean section were included in the study. The patient age, years since married, gravidity, parity, gestational age at time of cesarean section, ultrasound (placental position) and history of previous cesarean section(s) were collected. The evaluation also included mode of delivery whether hysterectomy or cesarean section was done electively or in emergency, placenta removed or not were included. Maternal outcomes or morbidity included estimated blood loss during surgery and units of packed red blood cell transfusion given with any transfusion complication. The blood loss was calculated from the number of gauze pads soaked with blood during the surgery. The morbidity also included postpartum anemia, post-surgical infection, urinary tract injuries, psychological illness and cesarean hysterectomy. Data pertaining to neonatal outcome included gender, birth weight, Apgar score at 1 and $5 \mathrm{~min}$, need for admission to NICU and any neonatal death were also recorded. In this hospital; surgeries for PA was managed by the obstetric consultant and a second consultant as emergency handling. The woman with PA was also evaluated prior to surgery by the urologist for insertion of a ureteric stent if required and by the vascular surgeon. Communication with blood bank personnel for supply of blood and blood products was also made forehand. The elective cesarean section was planned at 36-38 weeks if PA was suspected. All this data was recorded in SPSS version 23 and descriptive analysis was performed for all demographic variables, to find the association chi square was performed to assess various neonatal and maternal outcomes. P value $<0.005$ was statistically significant.

\section{RESULTS:}

A total of 111 patients with Placenta Previa (PP) were included in the study with the rate of $6 / 1000$ from the total 18000 deliveries performed during the study period. The PP was confirmed on operative findings, complete PP was noticed in 65 cases, partial in 24 cases, marginal in 17 cases and low lying PP in four cases. PA was found in 37 patients from 111 patients of PP and 74 were without PA with the rate of approximately $2 / 1000$ and 4/1000 respectively were included in the study. The mean age was $31.16 \pm 2.65$ (range 22-37) years, mean gravidity of $3.69 \pm 1.40$ (range 1 - 9), mean parity $2.57 \pm 1.01$ (range $1-5$ ), mean number of cesarean sections $2.10 \pm 0.66$, (range 1-3) and a mean gestational age at the time of cesarean section was $35.65 \pm 2.46$ (range 28-41) weeks. Majority of the patients $76(68.4 \%$ ) were reported in OPD and 35 patients (31.6\%) were brought in ER. Elective cesarean section was done in 52 patients $(46.8 \%)$ while emergency cesarean section was performed in $59(53.2 \%)$ patients. Nearly $21(57 \%)$ of PP patients with PA and 31(42\%) of PP patients without PA underwent planned cesarean section while $16(43 \%)$ and $43(58 \%)$ of PP patients with and without PA underwent emergency cesarean. An estimated $10(27 \%)$ of PP with PA had cesarean with hysterectomy so their fertility was not preserved. Cesarean hysterectomy was done in $17(15.3 \%)$ patients from which $10(27 \%)$ were performed in PP patients with PA and $7(9.5 \%)$ in PP without PA. Previous history of cesarean section was found in $37(69.4 \%)$ in PP with PA and 11(30.6\%) in PP without PA patients in this study. The statistically significant difference was observed while assessing the organ damaged in PP patients with PA and without PA which was 6(16.2\%) and $19(25.7 \%)$ respectively.

The data of this study revealed statistically significant difference in degree of Previa, injury to urinary system, number of previous Cesarean and DIC while comparing two cohorts of PP with PA and PP without PA and the calculated $\mathrm{P}$-value was $0.0001,0.004,0.0001$ and 0.0001 respectively. Table-1.

The blood loss assessed in entire population was $1350 \mathrm{ml}$ average, from which 500 to $999 \mathrm{ml}$ occurred in 11 patients $(9.9 \%), 1000$ to $1999 \mathrm{ml}$ occurred in 67 cases $(60.4 \%)$; $2000-3000 \mathrm{ml}$ in 24 (21.6\%); and $>2,000 \mathrm{ml}$ occurred in 09 $(8.1 \%)$ of the cases. The mean PRBC transfusion requirement was up to one pint in $09(8.1 \%)$ patients, $1-2$ units in $52(46.8 \%)$ patients, $2-3$ units in $19(17.2 \%)$ patients. The blood loss was more in patients of PP with PA compared to those without PA. The bleeding was controlled mostly by ligations of internal iliac artery or bilateral uterine artery ligation. Urinary tract injury occurred in $47(42.3 \%)$ patients, $32(28.8 \%)$ patients showed psychological effects, $09(8.1 \%)$ suffered from renal tubular necrosis, and 03 patients $3(2.7 \%)$ suffered disseminated intravascular coagulation (DIC). There was no maternal mortality.

For evaluating the fetal outcomes; a statistically significant result ( $\mathrm{p}=0.0001$ ) was observed while evaluating weight of neonate at different gestational age among patients of PP with PA and without PA. A similar trend was observed when neonate Apgar score was compared at 01 minutes $(\mathrm{p}=0.0001)$ and at five minutes it was $(\mathrm{p}=0.109)$ among both groups of PP patients with PA and without PA.(Table-2)

To assess the correlation between various neonatal and maternal outcomes; a significant positive correlation was observed between gestational age and neonatal weight $(r=0.614, P=0.0001)$ and with Apgar score at 5 minute $(r=$ 
Samina Naseem Khattak, Umbreen Akram, Erum Pervaiz, Maria Anayat, Tahir Ahmad Munir, Naheed Akhter, Athar Ahmad Jan

\begin{tabular}{|c|c|c|c|c|}
\hline \multicolumn{5}{|l|}{ Degree of previa } \\
\hline Type 1 (low lying) & $04(3.6 \%)$ & $0(0 \%)$ & $04(5.4 \%)$ & \multirow{4}{*}{$0.0001^{*}$} \\
\hline Type II (marginal) & $17(15.2 \%)$ & $0(0 \%)$ & $17(23 \%)$ & \\
\hline Type III (partial) & $25(22.6 \%)$ & $03(8.1 \%)$ & $22(29.7 \%)$ & \\
\hline Type IV (complete) & $65(58.6 \%)$ & $34(91.9 \%)$ & $31(41.9 \%)$ & \\
\hline \multicolumn{5}{|c|}{ Injury to urinary system } \\
\hline Yes & $47(42.3 \%)$ & $23(62.2 \%)$ & $24(32.4 \%)$ & \multirow{2}{*}{$0.004 *$} \\
\hline No & $64(57.7 \%)$ & $14(37.8 \%)$ & $50(67.6 \%)$ & \\
\hline \multicolumn{5}{|c|}{ No. of previous cesarean } \\
\hline Nil & $75(67.6 \%)$ & $12(32.4 \%)$ & $63(85.1 \%)$ & \multirow{4}{*}{$0.0001^{*}$} \\
\hline 1 & $16(14.4 \%)$ & $11(29.7 \%)$ & $05(6.8 \%)$ & \\
\hline 2 & $14(12.6 \%)$ & $10(27 \%)$ & $04(5.4 \%)$ & \\
\hline 3 & $06(5.4 \%)$ & $04(10.8 \%)$ & $02(2.7 \%)$ & \\
\hline \multicolumn{5}{|l|}{ DIC } \\
\hline Yes & $03(2.7 \%)$ & $01(2.7 \%)$ & $02(5.4 \%)$ & \multirow{2}{*}{$0.0001 *$} \\
\hline No & $108(97.3 \%)$ & $36(97.3 \%)$ & $72(87.3 \%)$ & \\
\hline \multicolumn{5}{|l|}{ Placenta removed } \\
\hline Yes & $19(17.11 \%)$ & $07(18.9 \%)$ & $12(16.2 \%)$ & \multirow{2}{*}{0.791} \\
\hline No & $91(82.9 \%)$ & $30(81.1 \%)$ & $62(83.3 \%)$ & \\
\hline \multicolumn{5}{|l|}{ PP anemia } \\
\hline Yes & $70(63.1 \%)$ & $26(70.3 \%)$ & $44(59.5 \%)$ & \multirow{2}{*}{0.302} \\
\hline No & $41(36.9 \%)$ & $11(29.7 \%)$ & $30(40.5 \%)$ & \\
\hline \multicolumn{5}{|c|}{ Renal Tubular necrosis } \\
\hline Yes & $09(8.1 \%)$ & $02(5.4 \%)$ & $07(9.5 \%)$ & \multirow{2}{*}{0.715} \\
\hline No & $102(91.9 \%)$ & $35(94.6 \%)$ & $67(90.5 \%)$ & \\
\hline \multicolumn{5}{|l|}{ Psychological effects } \\
\hline Yes & $32(28.8 \%)$ & $11(29.7 \%)$ & $21(28.4 \%)$ & \multirow{2}{*}{0.240} \\
\hline No & $84(71.2 \%)$ & $31(70.3 \%)$ & $53(71.6 \%)$ & \\
\hline
\end{tabular}

Table 1: Maternal outcomes among patients of PP with PA and PP without PA

\begin{tabular}{|l|l|c|c|c|}
\hline \multicolumn{1}{|c|}{ Variable } & \multicolumn{1}{c|}{ N=111 } & PP with PA & PP without PA & P-value \\
\hline Weight & $2.64 \pm 0.39$ & $2.50 \pm 0.41$ & $2.72 \pm 0.37$ & 0.007 \\
\hline 1-minute Apgar score & $6.93 \pm 1.10$ & $6.37 \pm 1.34$ & $7.21 \pm 0.84$ & 0.000 \\
\hline 5-minute Apgar score & $8.60 \pm 1.16$ & $8.35 \pm 1.27$ & $8.72 \pm 1.10$ & 0.109 \\
\cline { 1 - 4 } NICU Admission & $12(10.8 \%)$ & $07(18.9 \%)$ & $05(6.8 \%)$ & \multirow{2}{*}{0.060} \\
\cline { 1 - 4 } Death & $03(2.7 \%)$ & $02(5.4 \%)$ & $01(1.4 \%)$ & \\
\hline
\end{tabular}

Table 2: Neonatal outcomes of Placenta Previa (PP) patients with PA and without PA

\begin{tabular}{|c|c|c|c|c|c|c|c|}
\hline & & $\begin{array}{c}\text { Gestational } \\
\text { age }\end{array}$ & $\begin{array}{c}\text { Neonatal } \\
\text { weight }\end{array}$ & $\begin{array}{c}\text { Apgar score 5 } \\
\text { minutes }\end{array}$ & Parity & $\begin{array}{c}\text { Apgar score 1 } \\
\text { minutes }\end{array}$ & $\begin{array}{c}\text { Previous cesarean } \\
\text { section }\end{array}$ \\
\hline \multirow{2}{*}{$\begin{array}{c}\text { Apgar score 5 } \\
\text { minutes }\end{array}$} & P. Correlation & $.277^{* *}$ & $.373^{* *}$ & 1 & $-.356^{* *}$ & $.648^{* *}$ & $-.316^{* *}$ \\
\cline { 2 - 8 } & P-value & .003 & .000 & & .000 & .000 & .001 \\
\hline
\end{tabular}

** Correlation is significant at the 0.01 level (2-tailed). *Correlation significant at 0.05

Table-3: Pearson's Correlation between Gestational and Neonatal Outcomes

$0.277, \mathrm{P}=0.003)$. The previous cesarean sections showed significant negative correlation with gestational age $(\mathrm{r}=$ $0.227, \mathrm{P}=0.017)$, neonatal weight $(\mathrm{r}=-0.366, \mathrm{P}=0.0001)$ and with Apgar score 5 minute $(r=-0.316, \mathrm{P}=0.001)$. Apgar score 1 showed a positive correlation with 5-minute Apgar score $(\mathrm{r}=0.648, \mathrm{P}=0.0001)$ while a negative correlation was 
Incidence And Risk Factors Of Maternal And Fetal Outcomes Among Patients Of Placenta Previa With And Without Placenta Accreta

noticed with parity $(\mathrm{r}=-0.258, \mathrm{P}=0.006)$. (Table-3).

\section{DISCUSSION:}

Our results showed significantly increased maternal morbidity in patients of Placenta Previa PP with PA and are in consistent with a number of studies ${ }^{3,9-12}$. The women are at great risk with previous cesarean delivery, rate of previous caesarean section, short interval between caesarean section and conception, and massive obstetric hemorrhage ${ }^{13-15}$.

Our result showed mean $1500 \mathrm{ml}$ blood loss as a result of PA in $78(69 \%)$ cases, in addition, mean PRBCs transfused packed red blood cells required was 3 units. These results are in agreement with Wright et al who reported a median blood loss of $1500 \mathrm{ml}$ and a median PRBCs transfusion requirement of 4 units in 77 patients undergoing hysterectomy for $\mathrm{PA}^{14}$. Wright et al reported a mean of a median of 4.5 units transfused in patients with PA. it is now globally accepted that patients with PA should undergo surgery by experienced multidisciplinary surgeons team with urologists, general Surgeons, gynecologic oncologists, and an interventional radiologist or at least a second obstetric consultant to take rapid action to control bleeding and in taking decision for hysterectomy must be present where facilities of other specialties are not available to minimize maternal and neonatal morbidity and mortality ${ }^{16-19}$.

About $90 \%$ patients of PP with PA and $89 \%$ of PP without PA were diagnosed on Gray scale ultra sonography that had a sensitivity of $77 \%-87 \%$, specificity of $96 \%-98 \%$, positive predictive value of $65 \%-93 \%$, and a negative predictive value of $98 \%$. Overall gray scale is sufficient and more sensitive to color Doppler or power Doppler to diagnose $\mathrm{PA}^{20-22}$. MRI though costly and require experience and expertise but help in clarification of suspected cases of PA. In our study $9 \%$ cases of PP were diagnosed by MRI.

Our results showed that patients with PA have greater age, gravidity and parity than without PA. The results are in agreement with Dandanet $\mathrm{al}^{23}$ who reported that Placenta Accreta grows stronger as parity increases even if the numbers of cesarean sections are kept constant. Surraya et $\mathrm{al}^{24}$ observed parity as an independent factor for PA in his study. A significant increased number of previous cesarean section in patients with PA compared to patients in the absence of PA was seen in our result which were in agreement with a number of studies resulted in increased possibility of PA with increased and subsequent deliveries whether vaginal or cesarean. As the rate of PA rises with rising cesarean rates since the last few decades therefore, the rate of primary and repeated cesarean sections should be decreased without increase in maternal-fetal morbidity and mortality. By reducing cesarean section and encouraging vaginal delivery after cesarean section with counseling the patients explaining the complications of repeat cesarean section can improve the situation in $\mathrm{PA}^{15,25-27}$.

In our study $27(73 \%)$ cases of PP with PA and 36 (48\%) cases of PP without PA underwent cesarean section. To significantly improve fetal maturity and to decrease fetal morbidity, the pregnancy should be carried as close to full term as possible. An elective surgery was done in $47 \%$ of patients with PA in our study, an attempt to avoid emergent surgery as some institutions justify elective surgery at 34-35 weeks to decreased neonatal morbidity ${ }^{28-30}$.

In our study no neonate was small for gestation, however, half of our patients belonging to PA delivered before 36 weeks and more than $17 \%$ of newborns were admitted to the neonatal intensive care unit out of which 3 babies died. Our results are in consistent with Offer et $\mathrm{al}^{31}$ who showed that not only females with placenta accrete had $75 \%$ preterm birth rate and were managed with planned caesarean section; but the preterm birth rate was also much higher among those with PP. ${ }^{33}$

A study carried out at Civil Hospital Karachi ${ }^{32}$ reported neonatal mortality rate of $14 \%$ for placenta previa patients with maternal mortality of $2 \%$, while a study done at Hameed Latif Hospital Lahore ${ }^{4}$, reported $23.38 \%$ neonatal mortality in cases of PP. The neonatal complications associated with PP patients include respiratory distress syndrome and congenital anomalies. A low 1-minute Apgar score but an improved 5-minute Apgar score, an increase in neonatal weight with increase in gestational weeks in our results are in association with other studies.

\section{CONCLUSION:}

It is recommended that PA should be excluded in every case of PP to decrease the risk of feto-maternal morbidity and mortality. Planned delivery and intervention is necessary by multidisciplinary specialist team for women with placenta accreta.

\section{REFERENCES:}

1. Jacques Balayla. Placenta accreta and the risk of adverse maternal and neonatal outcomes.J Peri Med 2017,41(2):1-9.

2. Gibbins KJ, Einerson BD, Varner MW, Silver RM. Placenta previa and maternal hemorrhagic morbidity.J Matern Fetal Neonatal Med. 2018 ;31(4):494-499. doi: 10.1080/14767058. 2017.1289163 .

3. Hyunjin ho. The Risk Factors for Antenatal Bleeding in Pregnancy with Placenta Previa. J Preg Child Health 2017;4: 1-4 DOI: 10.4172/2376-127X.1000362.

4. FauziaAnjum, Rabia Bashir, Arooba Rahim. Maternal and Foetal Outcome in Cases of Placenta Previa, Accreta and Increta. JKEMU 2016; 22: 23-28.

5. Cynthia MF, Zhuoyang Li, Sarah L, Claire Mc, Wendy P, Michael JP. Incidence, risk factors and perinatal outcomes for placenta accreta in Australia and New Zealand: a casecontrol study. BMJ Open 2017;7:e017713. doi:10.1136/ bmjopen-2017-017713

6. Farquhar CM, Li Z, Lensen S, McLintock C, Pollock W, Peek $\mathrm{MJ}$, et al. Incidence, risk factors and perinatal outcomes for placenta accreta in Australia and New Zealand: a case-control study. BMJ Open. 2017; 7(10):e017713

7. Midori Fujisaki, Seishi Furukawa, Yohei Maki, Masanao 
Oohashi, KoutarouDoi, Hiroshi Sameshima. Maternal Morbidity in Women with Placenta Previa Managed with Prediction of Morbidly Adherent Placenta by Ultrasonography. J Pregnancy. 2017: 8318751. doi: 10.1155/2017/8318751

8. Kathryn J, Shawna R. Multidisciplinary Approach to Reduce the Risk of Morbidity and Mortality Related to Placenta Accreta 2015;44:83-84 https://doi.org/10.1111/15526909.12592

9. Walker MG, Allen L, Windrim RC, Kachura J, Pollard L, Pantazi S. Multidisciplinary management of invasive placenta previa.J ObstetGynaecol Can. 2013;35(5):417-425. doi: 10.1016/S1701-2163(15)30932-4.

10. Su HW, Yi YC, Tseng JJ, Chen WC, Chen YF, Kung HF, Chou MM. Maternal outcome after conservative management of abnormally invasive placenta.Tai J ObsGynecol, 2017, 56, $353-357$

11. Ferdous Ch, Mahbuba A, Rokeya K, Morzina B, Mahbuba S, Saida A. Management Strategies and Maternal Outcome of Placenta Accreta. Bangladesh J ObstetGynaecol, 2013; 28(2) : 71-75

12. Lyu B, Chen M, Liu XX. Risk factors of peripartum hysterectomy in placenta previa: a retrospective study of 3 840 cases.Zhonghua Fu Chan KeZaZhi. 2016; 51(7):498-502.

13. Belfort MA, Shamshiraz AA, Fox K. Minimizing blood loss at cesarean-hysterectomy for placenta previa percreta.Am J Obstet Gynecol. 2017;216(1):78.e1-78.e2. doi: 10.1016/j.ajog. 2016.10.030.

14. Wright JD, Pri-Paz S, Herzog TJ, Shah M, Bonanno C, Lewin $\mathrm{SN}$, et al.Predictors of massive blood loss in women with placenta accreta. Am J Obstet Gynecol. 2011;205(1):38.e16. doi: 10.1016/j.ajog.2011.01.040.

15. Paula S, Samantha K, Michael M, Jennifer D, Chad G, Jessie E, et al. Multidisciplinary approach to manage antenatally suspected placenta percreta: updated algorithm and patient outcomes Gynecologic Oncology Research and Practice 2017,4:11-18 https://doi.org/10.1186/s40661-017-0049-6

16. Shawky M, AbouBieh E, Masood A. Gray scale and Doppler ultrasound in placenta accreta: Otimization of ultrasound signs. Egyp J RadiolNuc Med. 2016, 47, 1111-1115

17. A Kilcoyne. MRI of Placenta Accreta, Placenta Increta, and Placenta Percreta - AJR 2017;12:345-51

18. Humayun S, Nahid F. Comparison of pregnancy outcome among placenta previa and abruption. Ann king Edward med uni 2015; 11: 58-9

19. Hong JY, Jee YS, Yoon, Kim SM. Comparison of general and epidural anesthesia in eective cesarean section for placenta previatotalis: maternal hemodynamics, blood loss and neonatal outcome. Intl J ObstetAnesth. 2003; 12: 12-6.
20. Gamal AK, Ali KA. Maternal and neonatal outcomes of placenta previa and placenta accreta: three years of experience with a two-consultant approach. Inter J Women Health 2013:5 803-810

21. Mullen CR, Battarbee AN, Ernst LM, Peaceman AM. Focal Placenta Accreta: Risk Factors, Adverse Obstetrical Outcomes, and Recurrence in Subsequent Pregnancies. Obstetrics \& Gynecology: 2017doi: 10.1097/01.AOG.0000514641.07268.ca

22. Gamal A Kassem, Ali K Alzahrani. Maternal and neonatal outcomes of placenta previa and placenta accreta: three years of experience with a two-consultant approachInt J Womens Health. 2013; 5: 803-10.doi: [10.2147/IJWH.S53865]

23. Zhang D, Yang S, Hou Y, Su Y, Shi H, Gu W. Risk factors, outcome and management survey of placenta accreta in 153 cases: a fve-year experience from a hospital of Shanghai, China Int J ClinExp Med 2017; 10(8):12509-16

24. Halimi S. Association of placenta previa with multiparity and previous cesarean sections. JPMI 2011; 25(02):139-142

25. Polat I, Yücel B, Gedikbasi, Aslan H, Fendal A. The effectiveness of double incision technique in uterus preserving surgery for placenta percreta.BMC 2017,17:129-32 https://doi.org/10.1186/s12884-017-1262-3.

26. Gibbins KJ, Einerson BD, Varner MW, Silver RM. Placenta previa and maternal hemorrhagic morbidity.J Matern Fetal Neonatal Med. 2018;31(4):494-99.

27. Oya A, Nakai A, Miyake H, Kawabata I, Takeshita T.Risk facors for peripartum blood transfusion in women with placenatprevia: a retrospective analysis. J Nippon Med Sc. 2008; 75: 146-151

28. Desai R, Singh B, Garg R. Morbidly adherent placenta and its maternal and fetal outcome.Int J ReprodObstet Gynecol. 2017;6:1890-1893. DOI: http://dx.doi.org/10.18203/23201770

29. Theresia B, Gilead M, Joseph O, Dominic M, Michael J. Maternal and obstetric risk factors associated with preterm delivery at a referral hospital in northern-eastern Tanzania APJR 2016; 5(5): 365-370

30. Raja Rajeshwari R., Rubini M. Maternal and perinatal outcome in placenta previa - one year study in tertiary care center in Tamil Nadu, India.2016; 5: 2320DOI: http://dx.doi.org/ 10.18203/2320-1770.ijrcog20162673

31. Erez O, Novack L, Klaitman V, Weiss IE, Weisel RB, Dukler $\mathrm{D}$, et al. Early preterm delivery due to placenta previa is an independent risk factor for a subsequent spontaneous preterm birth. BMC Pregnancy Childbirth. 2012;12:82-7 doi: 10.1186/1471-2393-12-82

32. Saima AS, Gulfishan T, Nargis S, Aneela S, Farah SH, Kanwal AM. Perinatal Outcome and Near-miss Morbidity between Placenta Previa Versus Abruptio Placentae.J Coll Physicians Surg Pak. 2011;21(2):79-83. doi: 02.2011/JCPSP.7983 